14,13

\title{
Текстура поверхности и корреляции плотность-плотность в пленках адамантансодержащих полиимидов и сополиимидов
}

\author{
() Д.В. Новиков \\ Санкт-Петербургский государственный лесотехнический университет им. С.М. Кирова, \\ Санкт-Петербург, Россия \\ E-mail: dvnovikov65@mail.ru
}

(Поступила в Редакцию 2 июня 2016 г.)

По данным электронной микроскопии изучены пространственные корреляции наночастиц золота, полученных вакуумным термическим напылением металла на активированную бромом поверхность пленок адамантансодержащих полиимидов и сополиимидов на основе пиромеллитового ангидрида (PMDA), 4,4'-оксидианилина (ODA) и 1-аминоэтил-3-(4'-аминофенил)адамантана (AEAPhA), а также диангидрида $3,4,3^{\prime}, 4^{\prime}$-тетракарбоксидифенилоксида (ODPA), ODA и AEAPhA при вариации соотношения фрагментов ODA и AEAPhA. Показано, что с ростом отношения мольных долей [AEAPhA]/[ODA] изменяются текстура поверхности пленок, свободный объем, корреляционная длина и периодичность чередования плотности распределения частиц. При этом уменьшается ближний и растет дальний порядок в ансамблях частиц. Аналогично трансформируется надмолекулярная структура полимера в результате структурных переходов в аморфном состоянии ODPA-ODA-AEAPhA и мезоморфном PMDA-ODA-AEAPhA.

DOI: 10.21883/FTT.2017.05.44393.228

\section{1. Введение}

Адамантансодержащие ароматические полиимиды и сополиимиды $[1,2]$ являются термостойкими диэлектриками с повышенной окислительной и гидролитической стабильностью. Эти свойства обусловлены наличием в полимерной цепи объемных, жестких и гидрофобных адамантиленовых фрагментов.

В работах $[1,2]$ показано, что при увеличении содержания фрагментов адамантиленароматических диаминов в диаминной части макромолекулы плотность полимера уменьшается, а межцепное взаимодействие усиливается. Такие изменения указывают на структурные переходы по типу псевдофазового разделения за счет контактного взаимодействия [3] адамантиленовых фрагментов. При этом надмолекулярная структура полимера должна трансформироваться в направлении уменьшения ближнего и роста дальнего порядка. Подобные структурные переходы представляют особый интерес в связи с возможными изменениями свободного объема, текстуры полимера и периодичности флуктуаций плотности.

В работе [4] были представлены данные широкоугловой рентгеновской дифракции (WAXS), электронной микроскопии (EM), а также физико-механические характеристики пленок ряда образцов адамантансодержащих полиимидов и сополиимидов. Для ЕМ-анализа структуры поверхности пленок была использована методика декорирования золотом „химических меток“ хемосорбированного брома. Данная методика, применимая к аморфным и мезоморфным полиимидам [5], основана на предварительной активации поверхности за счет образования активных центров - молекулярных комплексов брома с электронодонорными функциональными группами макромолекул. В дальнейшем активные центры служат потенциальными зародышами наночастиц зо- лота при его вакуумном термическом напылении на исследуемую поверхность, а плотность распределения наночастиц флуктуирует подобно плотности упаковки макромолекул.

В работе [4] была рассчитана корреляционная длина флуктуаций плотности в образцах, однако не были затронуты такие важные аспекты исследования, как получение пространственных корреляционных функций „Плотность-плотность“, анализ текстуры поверхности пленок и ее зависимости от состава полимера, выявление количественных корреляций типа структура-свойства.

В настоящей работе по данным EM, изучено влияние состава адамантансодержащих сополиимидов на ближний и дальний порядок в пространственном распределении декорирующих наночастиц золота, параметры квазирешетки частиц, свободный объем и текстуру поверхности пленок. Цель работы - установление закономерностей структурных переходов в образцах при увеличении мольной доли фрагментов адамантиленароматических диаминов в диаминной части сополиимидов.

\section{2. Объекты и методы исследования}

Образцы сополиимидов на основе пиромеллитового ангидрида (PMDA), 4, 4'-оксидианилина (ODA) и 1-аминоэтил-3-(4'-аминофенил)адамантана (AEAPhA), а также диангидрида $3,4,3^{\prime}, 4^{\prime}$-тетракарбоксидифенилоксида (ODPA), ODA и AEAPhA были получены в ходе процесса, включающего синтез сополиамидокислот, формирование пленок толщиной $20-25 \mu \mathrm{m}$ из раствора полимера на стеклянной подложке и последующую термическую имидизацию пленок $[1,2]$. Образцы содержали до $100 \mathrm{~mol} \%$ фрагментов AEAPhA, распределенных стати- 
стически вдоль цепи, и отвечали формулам [4] ODPA-ODA-AEAPhA

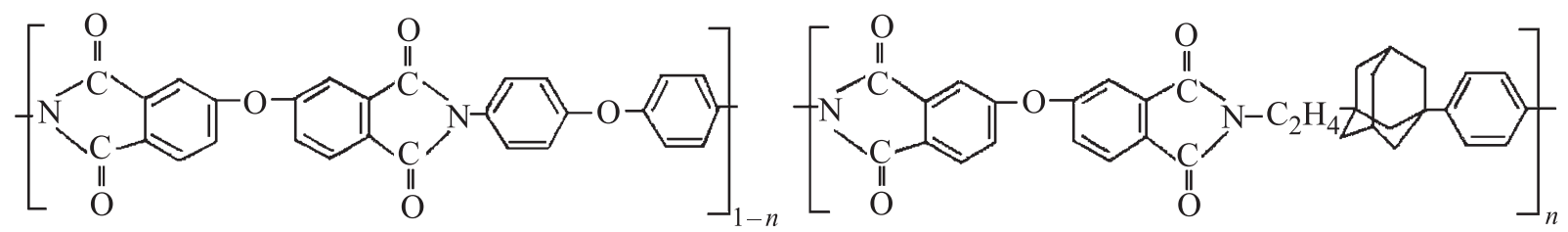

PMDA-ODA-AEAPhA

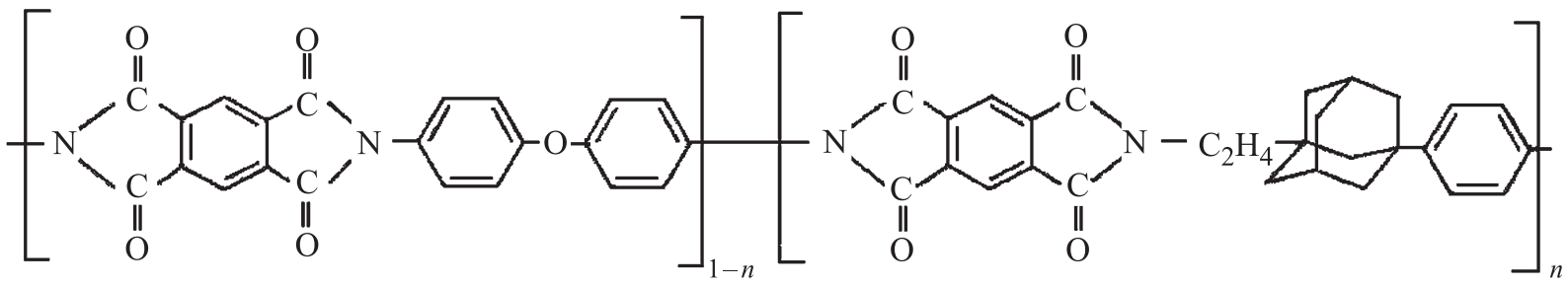

Препарирование образцов для ЕМ осуществлялось путем предварительной активации „воздушной“ поверхности пленок жидким бромом по методике [5] с последующим вакуумным (при давлении $10^{-3} \mathrm{~Pa}$ ) термическим напылением золота.

Наночастицы золота отделялись от поверхности с помощью опорной угольной реплики и изучались в просвечивающем электронном микроскопе EMV100L. Двумерные изображения декорированной поверхности $\left(2 \times 2 \mu \mathrm{m}^{2}\right)$ подвергались компьютерной оцифровке и включали при этом не менее 5000 частиц.

Для определения ближнего порядка использована радиальная функция $g(R)$ распределения частиц, получаемая сканированием изображения с шагом $\delta \sim 6 \mathrm{~nm}$, существенно меньшим наиболее вероятного расстояния $r$ между частицами. Дальний порядок и корреляционная длина $\xi$ определялись с помощью „крупнозернистой“ функции $g(R)$, полученной при величине $\delta \geq r$ [6].

Индикатрисы плотности $\rho$ распределения частиц получены при усреднении по прямоугольникам $2 r \cdot \xi$ с центром в частицах и изменении угла $\theta$ ориентации прямоугольников [7]. Периоды чередования плотности по направлениям осей текстуры образцов определены с использованием соответствующих функций $g(R)$.

\section{3. Результаты и их обсуждение}

Декорирующие наночастицы золота имеют довольно широкое распределение по размеру $(4-150 \mathrm{~nm})$, отражающее неоднородный энергетический микрорельеф поверхности полимерных пленок.

Для образцов ODPA-ODA-AEAPhA (рис. 1) с ростом отношения $[\mathrm{AEAPhA}] /[\mathrm{ODA}]$ мольных долей фрагментов AEAPhA и ODA усиливается микронеоднородность поверхности пленок: увеличивается доля участков с пониженной локальной плотностью распределения более крупных частиц золота, образованных за счет коа- лесценции мелких. Такая трансформация декорированной золотом поверхности полимера свидетельствует [5] о возрастании доли свободного объема и объясняется внедрением адамантиленовых фрагментов в макромолекулы полиимида, находящегося в аморфном фазовом состоянии $[4,8]$.

В случае образцов PMDA-ODA-AEAPhA, напротив, при увеличении отношения [AEAPhA]/[ODA] плотность распределения декорирующих частиц растет, а доля крупных частиц уменьшается [4]. Причиной этого является мезоморфный характер полиимида PMDA-ODA, мезофаза которого формируется агрегатами ориентированных в плоскости макромолекул $[9,10]$. При внедрении в PMDA-ODA фрагментов AEAPhA, за счет дополнительных взаимодействий между ними, объемная доля бесконечного кластера мезофазы полимера возрастает, а размер полостей кластера падает.

C ростом мольной доли фрагментов AEAPhA в образцах сополиимидов уменьшается ближний порядок в ансамблях частиц. Для образцов ODPA-ODA-AEAPhA рост интенсивности пика радиальной функции $g(R)$ распределения частиц сопровождается значительным его уширением (рис. 2,a), свидетельствующим об ослаблении пространственных корреляций между частицами, увеличении координационного числа, а также информационной энтропии квазирешетки частиц $[6,11]$. Уменьшение ближнего порядка в случае образцов PMDA-ODA-AEAPhA выражается в падении интенсивности пика функции $g(R)$ (рис. $2, b)$. При этом для двух сополиимидов наиболее вероятное расстояние $r$ между наночастицами золота закономерно уменьшается (рис. 2). Это связано с ростом числа активных центров образования наночастиц на бромированных адамантиленовых группировках.

Как показано в работах $[1,2,4]$, с ростом отношения $[\mathrm{AEAPhA}] /[\mathrm{ODA}]$ в исследуемых образцах сополиимидов плотность пленок падает, а среднее расстояние между 

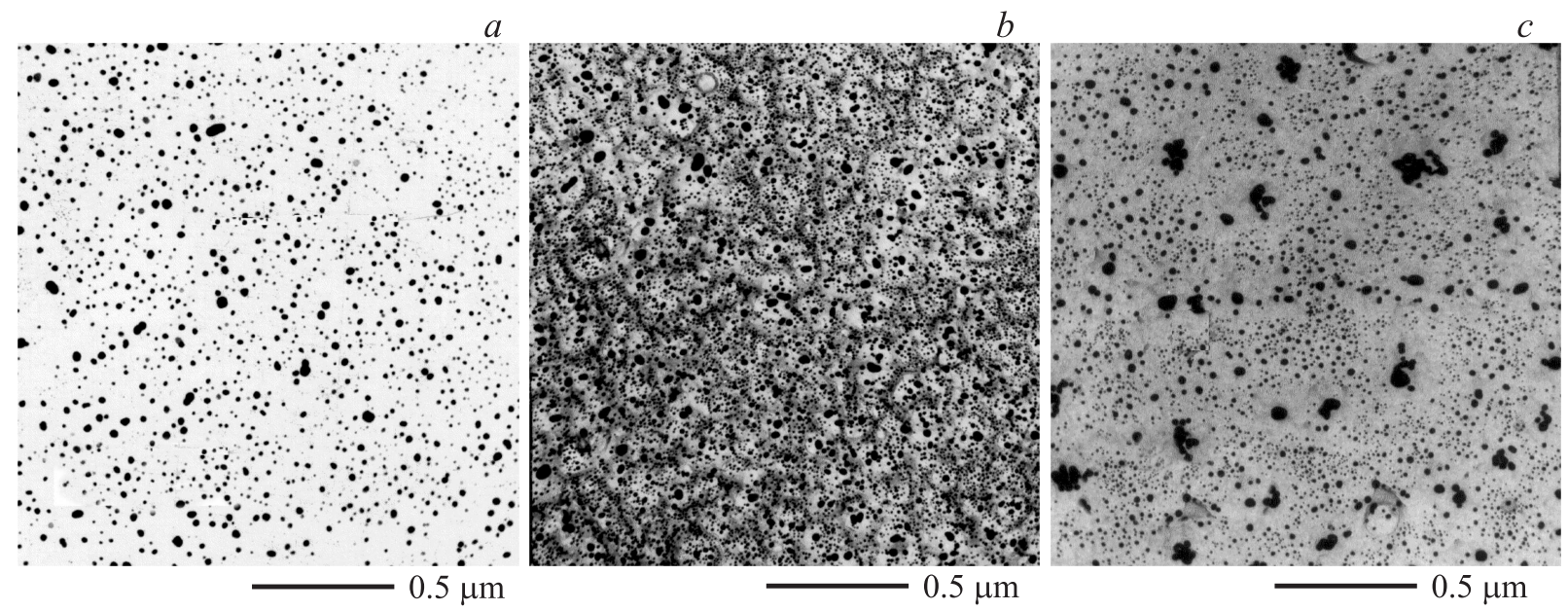

Рис. 1. Электронные микрофотографии декорированной золотом поверхности пленок ODPA-ODA-AEAPhA. Образцы соответствуют отношению $[\mathrm{AEAPhA}] /[\mathrm{ODA}], \mathrm{mol} \%: 0: 100(a), 50: 50(b)$ и 100:0 (c).
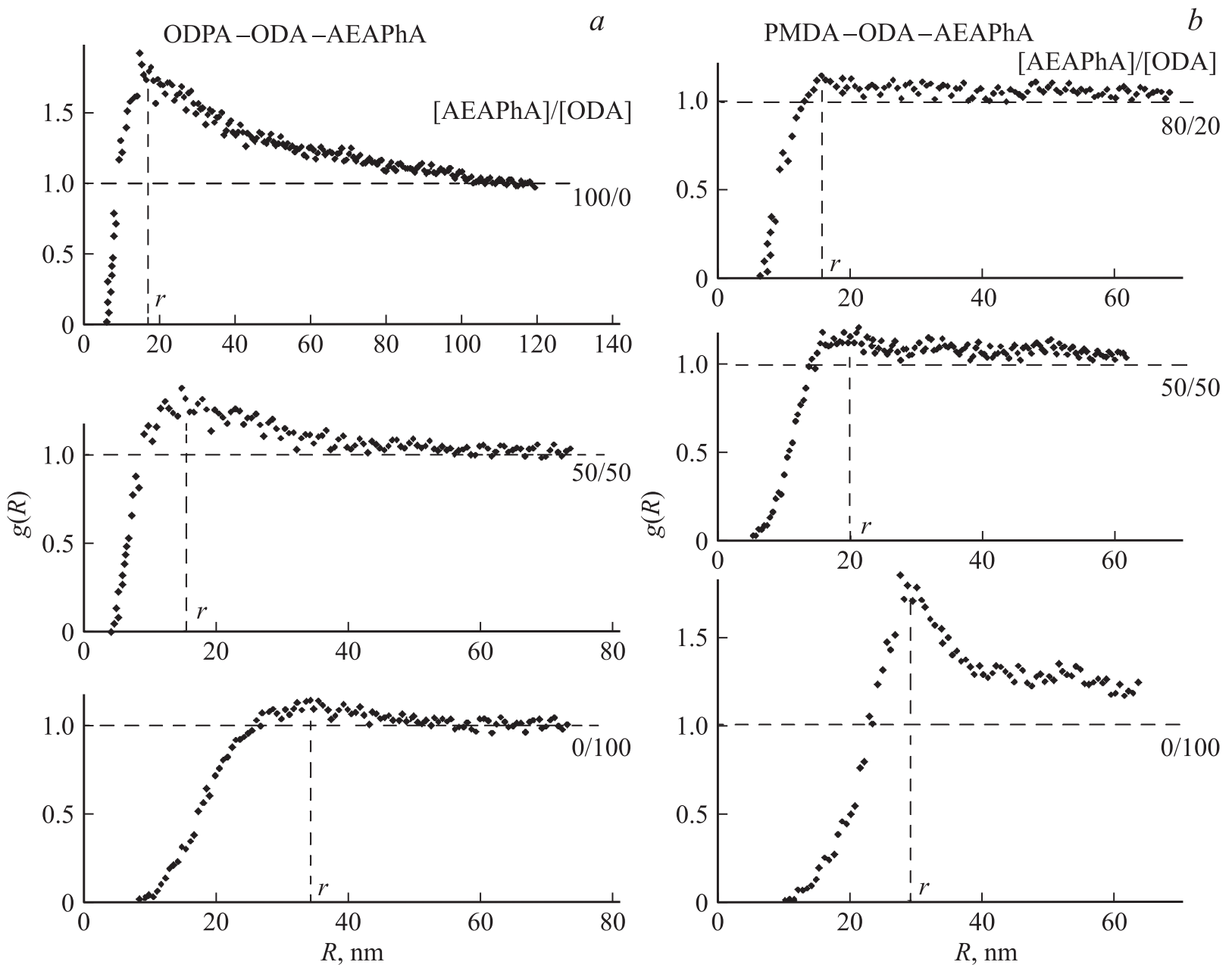

Рис. 2. Радиальные функции $g(R)$ распределения наночастиц золота на поверхности пленок сополиимидов: ODPA-ODAAEAPhA $(a)$; PMDA-ODA-AEAPhA $(b)$. 

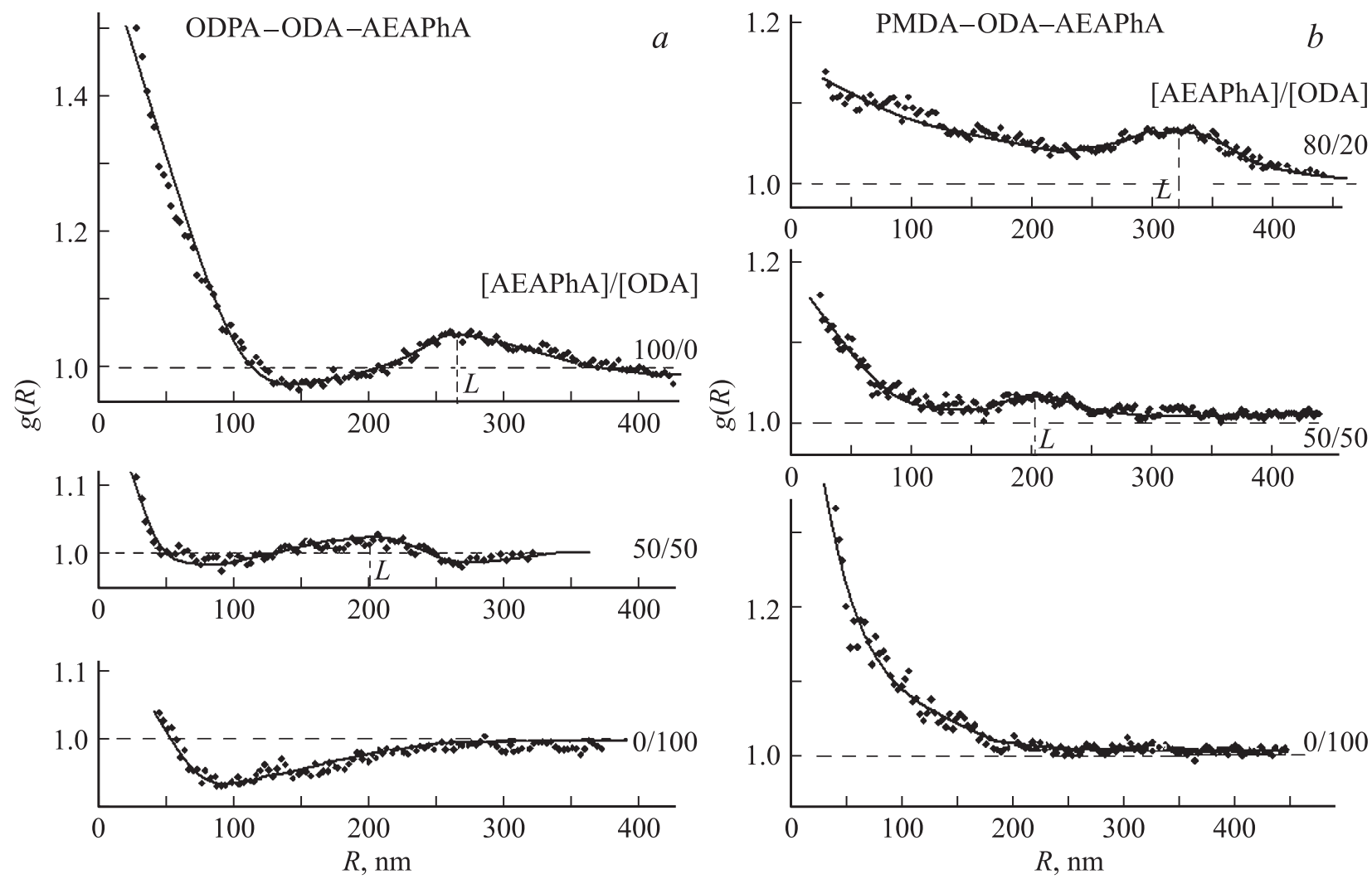

Рис. 3. Радиальные функции $g(R)$ распределения плотности наночастиц золота на поверхности пленок сополиимидов: ODPA-ODA-AEAPhA $(a)$; PMDA-ODA-AEAPhA $(b)$.

цепями макромолекул увеличивается. Эти данные также подтверждают уменьшение ближнего порядка, при котором в образцах ODPA-ODA-AEAPhA увеличивается свободный объем [8], а в образцах PMDA-ODAAEAPhA нарушается [4] планарная структура кластера мезофазы в результате внедрения в него объемных фрагментов AEAPhA.

На поверхности пленок адамантансодержащих образцов наблюдается дальний порядок в чередовании наночастиц золота. Периодичность локальной плотности распределения частиц с периодом $L$ обнаруживается при построении функции $g(R)$ с шагом $\delta=30 \mathrm{~nm}$ (рис. 3). При [AEAPhA]/[ODA] $=0$ периодичность отсутствует, и функции $g(R)$ на масштабе корреляционной длины $\xi \sim 350 \mathrm{~nm}$ приближаются к прямой $g(R)=1$, что происходит по-разному для двух образцов полиимидов. В случае ODPA-ODA функция $g(R)$ является немонотонной, типичной для структурно-неоднородных систем (рис. 3,a). В свою очередь, полиимид PMDA-ODA является однородно неупорядоченным, и функция $g(R)$ монотонно убывает, приближаясь к прямой $g(R)=1$ (рис. 3,b). Отметим, что величина $\xi$ порядка сотен $\mathrm{nm}[12]$ соответствует гидродинамическому радиусу агрегатов макромолекул ароматического полиимида в пленкообразующем растворе в момент образования непрерывной физической сетки зацеплений макромолекул. В адамантансодержащих образцах поли- имидов и сополиимидов функции $g(R)$ имеют максимум, отвечающий периоду $L$ чередования плотности, равному корреляционной длине $\xi$. С ростом отношения [AEAPhA]/[ODA] величина максимума увеличивается (рис. 3), что соответствует росту дальнего порядка. Такое изменение функций $g(R)$ можно объяснить псевдофазовым разделением в полимере за счет контактного взаимодействия адамантиленовых фрагментов. Сопутствующие структурные переходы имеют свою специфику в зависимости от фазового состояния полимера.

На рис. 4 представлены индикатрисы относительной плотности $\rho$ распределения наночастиц золота на поверхности образцов пленок с различным отношением $[\mathrm{AEAPhA}] /[\mathrm{ODA}]$. Полученные угловые зависимости $\rho(\theta)$ позволяют определить характер текстуры поверхности пленок.

Поверхность пленки полиимида ODPA-ODA $([\mathrm{AEAPhA}] /[\mathrm{ODA}]=0 / 100) \quad$ имеет $\quad$ слабовыраженную биаксиальную текстуру (рис. 4, $a$ ), и функции $g_{\|}(R)$ и $g_{\perp}(R)$, построенные соответственно по направлениям c максимальной и минимальной локальной плотностью частиц (рис. 5,a), аналогичны усредненной функции $g(R)$ (рис. 3, $a$ ). Такую поверхность можно считать квазиизотропной, типичной для аморфного полимера. Аморфный характер полиимида ODPA-ODA подтверждается дифрактограммой WAXS [4]. В образце ODPA$\mathrm{ODA}-\mathrm{AEAPhA} \quad([\mathrm{AEAPhA}] /[\mathrm{ODA}]=50: 50) \quad$ наблю- 


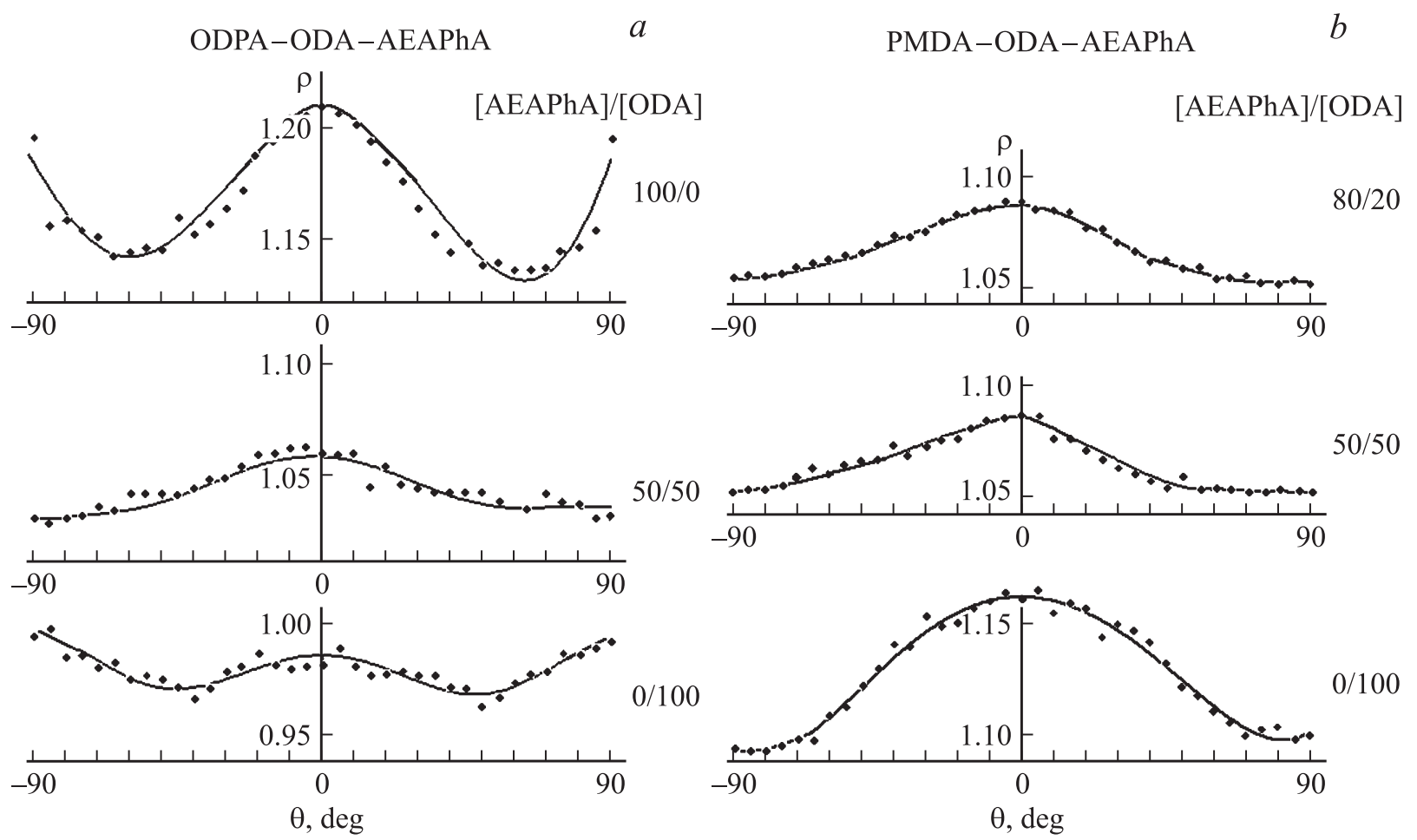

Рис. 4. Индикатрисы относительной (по отношению к средней по поверхности) плотности $\rho$ распределения наночастиц золота на поверхности пленок сополиимидов: ODPA-ODA-AEAPhA $(a)$; PMDA-ODA-AEAPhA $(b)$. Ось ординат $(\theta=0$ градусов) соответствует оси текстуры.

$a$

$b$
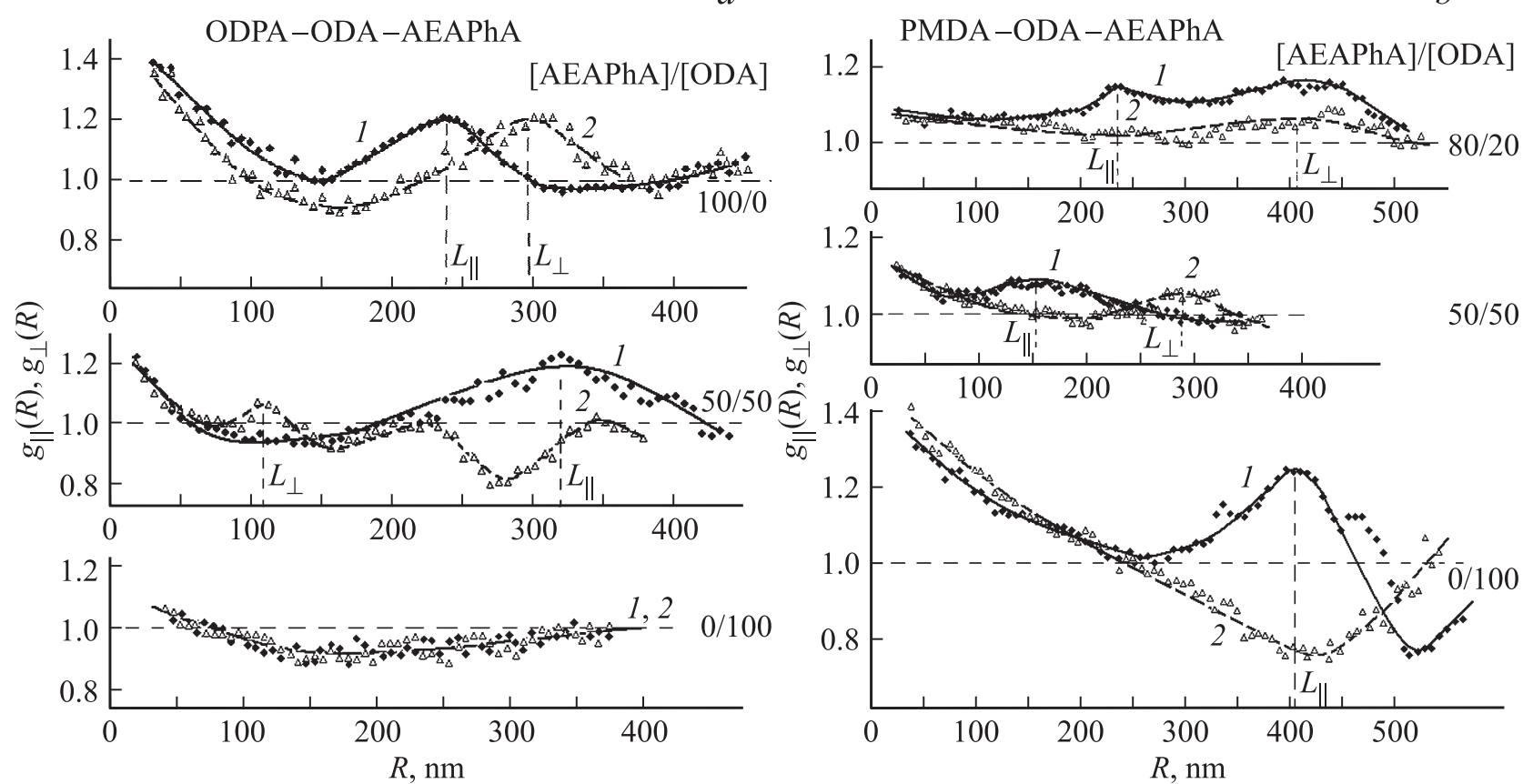

Рис. 5. Радиальные функции распределения плотности, построенные по направлениям с максимальной $\left(g_{\|}(R)-\right.$ кривая 1$)$ и минимальной $\left(g_{\perp}(R)\right.$ - кривая 2$)$ локальной плотностью частиц на поверхности пленок сополиимидов: ODPA-ODA-AEAPhA $(a)$; PMDA-ODA-AEAPhA $(b)$. 
дается анизотропия плотности и, как следствие, аксиальная текстура поверхности. Отличие в плотностях вдоль и поперек оси текстуры составляет не более $3 \%$ (рис. 4, $a$ ). При этом периоды чередования плотности вдоль $\left(L_{\|}\right)$и поперек $\left(L_{\perp}\right)$ оси текстуры (направления с максимальной локальной плотностью частиц) отличаются между собой в три раза (рис. 5,a), а их среднее значение соответствует корреляционной длине $\xi$. Известно [13], что в пленках ароматических полиимидов часто возникает оптическая анизотропия, которая может являться следствием различных причин: ориентационных эффектов, образования мезофаз, внутренних механических напряжений, кристаллизации полиимида. С учетом рентгеноаморфного характера сополиимидов ODPA-ODA-AEAPhA [4] можно полагать, что анизотропия плотности появляется в данном случае за счет дополнительного взаимодействия фрагментов AEAPhA. Поверхность пленки полиимида ODPA-AEAPhA ([AEAPhA $] /[\mathrm{ODA}]=100 / 0)$ характеризуется выраженной биаксиальной текстурой (рис. 4,a). В данном образце также наблюдается периодичность чередования плотности, но периоды $L_{\|}$и $L_{\perp}$ различаются между собой только на $20 \%$ (рис. 5, $a$ ). Поэтому поверхность образца ODPA-AEAPhA можно считать квазиизотропной. Таким образом, при внедрении фрагментов AEAPhA в диаминную часть полиимида ODPA-ODA происходят структурные переходы в аморфном состоянии полимера, при этом с ростом отношения [AEAPhA] $/[\mathrm{ODA}]$ немонотонно изменяются текстура поверхности пленок, корреляционная длина $\xi$ и периоды $L_{\|}$и $L_{\perp}$ вдоль осей текстуры.

Поверхность пленки полиимида PMDA-ODA $([\mathrm{AEAPhA}] /[\mathrm{ODA}]=0 / 100)$ имеет выраженную аксиальную текстуру, при этом плотности вдоль и поперек оси текстуры отличаются на 7\% (рис. 4,b). Вдоль оси текстуры наблюдается периодичность распределения плотности с периодом $L_{\|} \sim 400 \mathrm{~nm}$, а поперек оси такая периодичность отсутствует (рис. 5,b). Полученные данные свидетельствуют о мезоморфном характере структуры PMDA-ODA. Такой вывод подтверждается дифрактограммой WAXS, содержащей дополнительный к аморфному гало четкий рефлекс, который соответствует периоду чередования фрагментов цепи [4,13]. Интенсивность рефлекса существенно возрастает при отжиге пленок выше температуры стеклования полимера [4]. В сополиимидах PMDA-ODA-AEAPhA с ростом отношения $[\mathrm{AEAPhA}] /[\mathrm{ODA}]$ аксиальная текстура становится менее выраженной (рис. 4,b). Последнее объясняется увеличением объема кластера мезофазы за счет взаимодействия фрагментов AEAPhA. Образцы, отвечающие $[\mathrm{AEAPhA}] /[\mathrm{ODA}]=50 / 50$ и $80 / 20$, характеризуются периодическим распределением плотности вдоль и поперек оси текстуры, причем периоды $L_{\|}$и $L_{\perp}$ существенно отличаются друг от друга, а $\left(L_{\|}+L_{\perp}\right) / 2 \approx \xi$. Таким образом, с ростом содержания фрагментов AEAPhA в сополиимиде $\mathrm{PMDA}-\mathrm{ODA}-\mathrm{AEAPhA} \mathrm{происходят}$ структурные переходы в мезоморфном состоянии

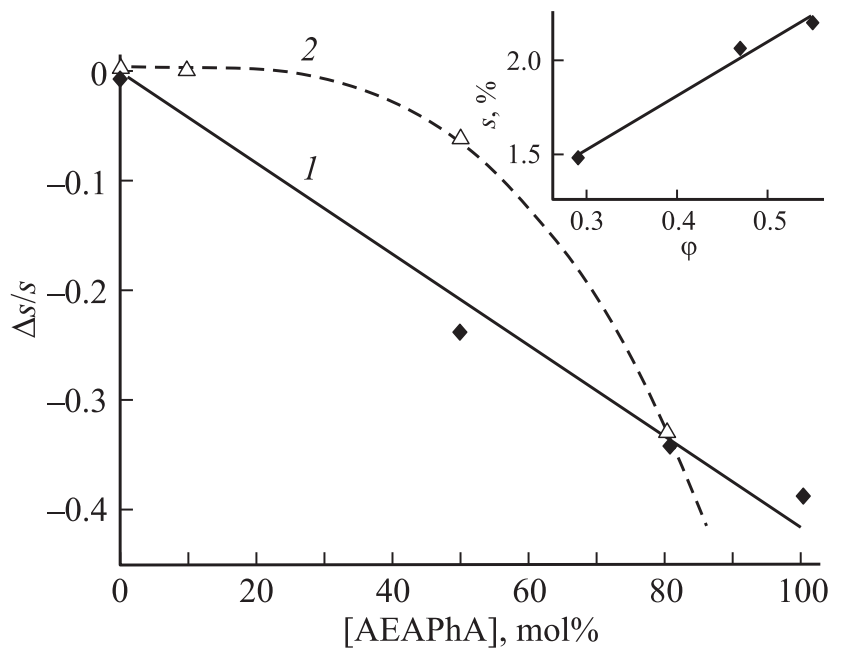

Рис. 6. Зависимости относительного изменения $\Delta s / s$ сорбции воды пленками от мольной доли фрагментов AEAPhA. Образцы сополиимидов: ODPA-ODA-AEAPhA (1); PMDA-ODA-AEAPhA (2). На вставке: зависимость массовой доли $s$ абсорбированной воды от доли $\varphi$ свободного объема для образцов PMDA-ODA-AEAPhA.

полимера: объем кластера мезофазы возрастает, однако при этом увеличивается и плотность дефектов нарушений планарной упаковки макромолекул [4].

Различное фазовое состояние полиимидов ODPA-ODA и PMDA-ODA предопределяет специфику структурных переходов при внедрении адамантиленовых фрагментов в диаминную часть макромолекулы и обусловливает различные зависимости влагопоглощения пленок от мольной доли [AEAPhA] фрагментов $\mathrm{AEAPhA.} \mathrm{Как} \mathrm{известно} \mathrm{[1,2],} \mathrm{повышенная} \mathrm{гидролити-}$ ческая стабильность адамантансодержащих полиимидов и сополиимидов связана с их явно выраженными гидрофобными свойствами. При проведении гетерогенного гидролиза лимитирующим является процесс диффузии реагента к реакционным центрам. Одной из причин затрудненной диффузии воды в полимер является наличие в его структуре объемных гидрофобных адамантиленовых фрагментов.

На рис. 6 приведены построенные по данным [4] зависимости относительного изменения $\Delta s / s$ сорбции воды пленками от состава полимеров, где $\Delta s / s$ изменение массовой доли абсорбированной воды в образцах по отношению к исходным пленкам ODPA-ODA и PMDA-ODA. Уменьшение влагопоглощения с ростом $[\mathrm{AEAPhA}]$ происходит по-разному для двух сополиимидов: в случае ODPA-ODA-AEAPhA наблюдается линейное падение параметра $\Delta s / s$, а для PMDA-ODA-AEAPhA параметр $\Delta s / s$ снижается с ускорением. Отклонение от линейной зависимости во втором случае обусловлено влиянием надмолекулярной структуры полимера на влагопоглощение. В образце PMDA-ODA-AEAPhA при увеличении [AEAPhA] pacтет объемная доля кластера мезофазы, а доля $\varphi$ сво- 
бодного объема падает. Величину $\varphi$ можно оценить, поскольку она пропорциональна доле свободных узлов квазирешетки наночастиц золота, рассчитываемой на основании плотности $\rho$, координационного числа и расстояния $r$ между узлами [6]. Расчет показывает, что зависимость массовой доли $s$ абсорбированной воды от параметра $\varphi$ для образцов PMDA-ODA-AEAPhA является линейной (рис. 6, вставка), и, таким образом, мезоморфная структура полимера оказывает первостепенное влияние на влагопоглощение пленок. В случае аморфного образца ODPA-ODA-AEAPhA с ростом [AEAPhA] свободный объем увеличивается, и уменьшение влагопоглощения пропорционально [AEAPhA].

\section{4. Заключение}

При увеличении мольной доли [AEAPhA] фрагментов адамантиленароматических диаминов в диаминной части ароматического полиимида имеют место структурные переходы, сопровождающиеся уменьшением ближнего и ростом дальнего порядка. Такие переходы контролируются фазовым состоянием полимера и проявляются в изменении корреляционной длины, свободного объема, текстуры поверхности, а также периодичности чередования плотности. Возникающая периодичность, составляющая десятые доли $\mu \mathrm{m}$, объясняется псевдофазовым разделением в полимере за счет усиления межцепных контактных взаимодействий между адамантиленовыми фрагментами. Уменьшение относительного влагопоглощения полимерных пленок с ростом [AEAPhA] происходит по-разному для аморфного и мезоморфного сополиимида: пропорционально [AEAPhA] в первом случае при увеличении свободного объема $\varphi$, не препятствующего диффузии воды в полимер, и нелинейно во втором случае на фоне существенного падения $\varphi$.

\section{Список литературы}

[1] И.А. Новаков, Б.С. Орлинсон, Г.Е. Зайков, В.Г. Зайков. Пласт. массы 6, 28 (2002).

[2] И.А. Новаков, Б.С. Орлинсон. Высокомолекуляр. соединения С 47, 1302 (2005).

[3] В.А. Белошенко. Физика и техника высоких давлений 5, 75 (1995).

[4] T.E. Sukhanova, I.V. Gofman, A.I. Grigoriev, M.E. Vylegzhanina, D.V. Novikov, B.S. Orlinson, I.A. Novakov. In: Polyimides and Other High Temperature Polymers: synthesis, characterization and applications / Ed. K.L. Mittal. Utrecht, Boston, (2005). V. 3. P. 69.

[5] Д.В. Новиков, Т.Е. Суханова, В.М. Светличный, И.В. Гофман, А.И. Григорьев, А.Л. Диденко, Т.А. Маричева, В.В. Кудрявцев. Высокомолекуляр. соединения А 43, 655 (2001).

[6] Д.В. Новиков, А.Н. Красовский, В.Н. Филиппов. ФТТ 56, 2246 (2014).

[7] Д.В. Новиков, И.С. Курындин, V. Bukošek, Г.К. Ельяшевич. ФТT 54, 2173 (2012).
[8] И.А. Новаков, Б.С. Орлинсон, Р.В. Брунилин, Н.Н. Сигаева, В.А. Крайкин, В.П. Володина, Ю.Б. Монаков. Высокомолекуляр. соединения А 39, 1786 (1997).

[9] T.P. Russell, H.R. Brown. J. Polym. Sci. B 25, 1129 (1987).

[10] T.P. Russell. J. Polym. Sci. B 22, 1105 (1984).

[11] Дж. Займан. Модели беспорядка. Мир, М.: (1982). С. 443. [J.M. Ziman. Models of Disorder. Cambridge Univ. Press, London: (1979). 480 p.]

[12] Д.В. Новиков, А.Н. Красовский, В.Н. Филиппов, Т.Е. Суханова, В.М. Светличный. ЖПХ 76, 1160 (2003).

[13] М.И. Бессонов, М.М. Котон, В.В. Кудрявцев, Л.А. Лайус. Полиимиды - класс термостойких полимеров. Наука, Л. (1983). 328 c. 